\title{
Anthropogenic data question the concept of the Anthropocene as a new geological epoch
}

\author{
Retired nuclear scientist from Department of Nuclear Physics, The Australian National University, Canberra, ACT, 2601, Australia;
} E-mail: ronwnielsen@gmail.com

(Received: April 6, 2021; Revised accepted: July 23, 2021)

https://doi.org/10.18814/epiiugs/2021/021020

Anthropogenic indicators have been closely inspected to determine whether they can be used in support of the concept of the Anthropocene as a new geological epoch and of its proposed beginning around 1950 CE (Common Era), which is supposed to be marked by intensifications of human activities and impacts around that time. Data show that there were no systematic intensifications in growth trajectories describing anthropogenic indicators but there were decelerations suggesting that anthropogenic forces are not as strong as expected and, consequently, that they are probably not strong enough to have unequivocal stratigraphic manifestations of geological transition. Analysis of anthropogenic data suggests that the Anthropocene is not a new geological epoch.

\section{Introduction}

About twenty years ago, a new geological epoch created by humans, the Anthropocene, was proposed by Crutzen and Stoermer (2000). More recently, an interesting study has been presented by 18 authors from prominent academic institutions (Syvitski et al., 2020). They postulate that extraordinary human consumption of energy resulted in geological impacts commencing around $1950 \mathrm{CE}$ (Common Era) and initiating the proposed new geological epoch. Taking a more general view, from human consumption of energy to a wider scope of human activities, they postulate that there was an extraordinary acceleration (described by them as an extraordinary outburst) in consumption and productivity, which according to them demonstrated how the Earth System departed from its Holocene status since around $1950 \mathrm{CE}$. Thus, they offer a clear and assertive description of the mechanism of the proposed transition to a new geological epoch. It is an attractive proposition, but it is hard to accept it because it does not appear to be supported convincingly by data.

When discussing the Anthropocene, it is easy to show many examples of the intensity of human activities and impacts, illustrated by contrasting numerical values before and after a certain time. It is easy to be impressed by such presentations. However, how reliable are such examples in supporting the concept of a transition to a new geo- logical epoch? Fundamental and obvious property of growth trajectories is that they increase. It is, therefore, obvious that whatever is increasing was smaller before a certain, arbitrarily selected time, and larger after that time. Growth trajectories describing anthropogenic indicators were not only increasing but, in general, they were also increasing progressively faster, before they decelerated in the second half of the 20th century (Nielsen, 2021). For such trajectories, it is easy to find many examples of not only small and large values before and after an arbitrarily selected year, but also of slow and fast increase. Such examples do not prove that something unusual happened around that arbitrarily selected year. They only demonstrate what is already obvious that for the increasing and usually accelerating trajectories, values represented by them are increasing and that they are also increasing progressively faster. There is no profound revelation in presenting selected examples of such data and no far-reaching conclusions can be drawn from such presentations.

A reliable way of showing that there was an unusual increase around $1950 \mathrm{CE}$, or around any other time, which might give a certain degree of support for the concept of the departure of the Earth System to a new geological epoch, is by a careful study of time dependence of growth trajectories describing human activities and impacts. These trajectories would have to demonstrate a clear and coordinated intensification of growth (abrupt acceleration) at a certain time, a sharp increase in the gradient (slope) of the time-dependent growth trajectories at a specific time. The change in the slope of the curves should be strong and clear to justify the expectation of its unequivocal geological manifestation. However, even then, empirical demonstration of abrupt and sustained accelerations in the intensity of anthropogenic activities and in their corresponding environmental impacts would have to be supported by convincing stratigraphic records of a geological transition. Without such a support, even most convincing abrupt accelerations (sudden increase in the slopes of growth trajectories describing human activities and impacts) appear to be geologically irrelevant.

Geological transitions represent rare events, which are caused by unusually strong forces. To propose that for the first time in the existence of our planet, humans are causing transition to a new geological epoch is a strong declaration, which needs to be supported by an equally strong evidence in data. It has been suggested that it might be necessary to wait for a million years for such a convincing evidence, 
if any (Hamilton, 2015). However, attempts are now being made to speed up the process of recognition of the proposed new geological epoch. So far, these attempts appear to have been unsuccessful.

Two important issues associated with the concept of the Anthropocene as a new geological epoch are: (1) whether there is a convincing evidence that the Anthropocene is a new geological epoch and (2) whether there is a convincing evidence that there was an extraordinary acceleration in human activities and impacts around $1950 \mathrm{CE}$, or around any other recent time, that could be used to support the concept of geological transition and to mark its beginning. The first issue is complicated because it requires unequivocal evidence in stratigraphic records, which might be too early to expect. The second issue is significantly simpler because data describing human activities and impacts can be easily analysed. Recent analysis (Nielsen, 2021) of a large body of such data (Broadgate et al., 2014) demonstrated systematic decelerations around $1950 \mathrm{CE}$, i.e., around the time when systematic accelerations were expected.

The remarkable feature of the study of Syvitski et al. (2020) is that there is not even a single convincing example of a sustained intensification (acceleration) of growth around $1950 \mathrm{CE}$. In this respect, their publication is in agreement with all other previous publications on this topic: there is no proof of a common and sustained intensification of human activities and impacts around that time. Another remarkable feature is that these authors do not appear to have carried out rigorous analysis of data they have listed in their publication. They present many correlations between anthropogenic indicators, but these correlations do not show intensification of growth around $1950 \mathrm{CE}$. The aim of the study presented here is to extend the work of Syvitski et al. (2020) by the re-examination of data they have listed in their publication to see whether there is support for the concept of the proposed new geological epoch and of its postulated beginning around 1950 CE. This study is a part of a wider exploration of these issues and of their broader debate in the published literature. The examination of data is so simple that it does not even require mathematical analysis. However, results of rudimentary mathematical analysis are also presented, both here (Figs. 8-10) and in the Supplementary material (Figs. 1S, 2S, 4S, 5S, 7S and 8S).

\section{Three Most Important Indicators}

\section{Human Consumption of Energy}

The key figure in the article of Syvitski et al. (2020) is at the beginning of their publication. It presents global human consumption of primary energy, global growth of human population, and global economic growth. Data for the human consumption of energy, as listed by Syvitski et al. (2020), are presented here in Fig. 1. They extend to around 10,000 BCE (Before Common Era). It is convenient to display them using Years Before 2020 CE, as done by Syvitski et al. (2020). Anyone familiar with time-dependent trajectories will notice that data suggest hyperbolic growth, which is characterised by a nearly horizontal, and close to zero, growth over a long time and a nearly vertical growth over a short time, when presented using linear scales of reference, as in this display.

In their study, Syvitski et al. (2020) selected only certain data from significantly larger sets (Broadgate et al., 2014; Ritchie and Roser, 2016).
Annual Global Consumption of Primary Energy [EJ]

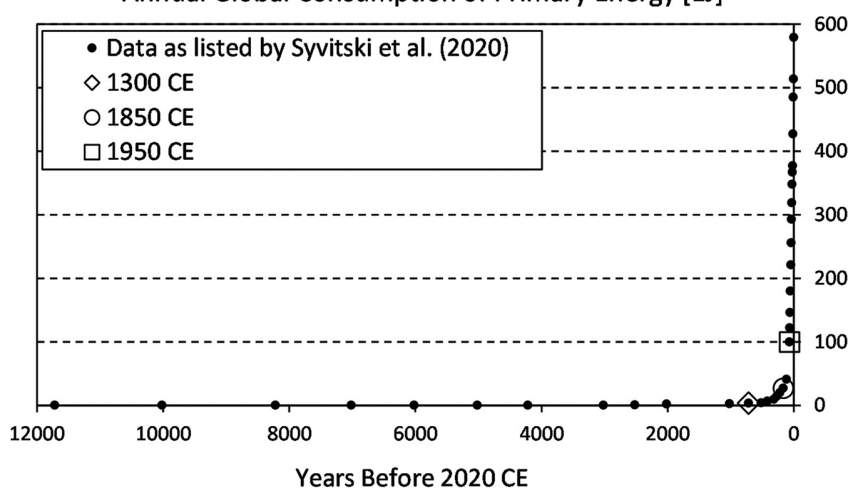

Figure 1. Human consumption of energy, in exajoules (EJ). There was no intensification of growth around $1950 \mathrm{CE}$, no transition to a faster trajectory around that time.

However, even their selected data suggest a monotonic (gradual) transition from a nearly horizontal to a nearly vertical growth. There was no intensification of growth around $1950 \mathrm{CE}$. Growth in $1950 \mathrm{CE}$ was already well advanced along the nearly vertical trajectory. If there was an intensification of growth at any specific time, then it must have been before $1950 \mathrm{CE}$. Indeed, data suggest that if one tried to imagine the time of the beginning of a transition from the nearly horizontal to the nearly vertical growth, then $1300 \mathrm{CE}$ would be a good candidate. In such a case, the beginning of the Anthropocene would be around $1300 \mathrm{CE}$. However, in order to use this year as a proposed beginning of a new pattern of growth, data around that time would have to be more closely examined.

A standard procedure for inspecting data varying over a large range of values, as it is in this case, is to use semilogarithmic display (logarithmic vertical axis and linear horizontal axis). Data for the human consumption of energy are shown in Fig. 2 using such a display. They are the same data as presented earlier in Fig. 1 but now over a shorter range of time. The essential difference between the two displays is in the vertical axis, which is now logarithmic to allow for a better inspection

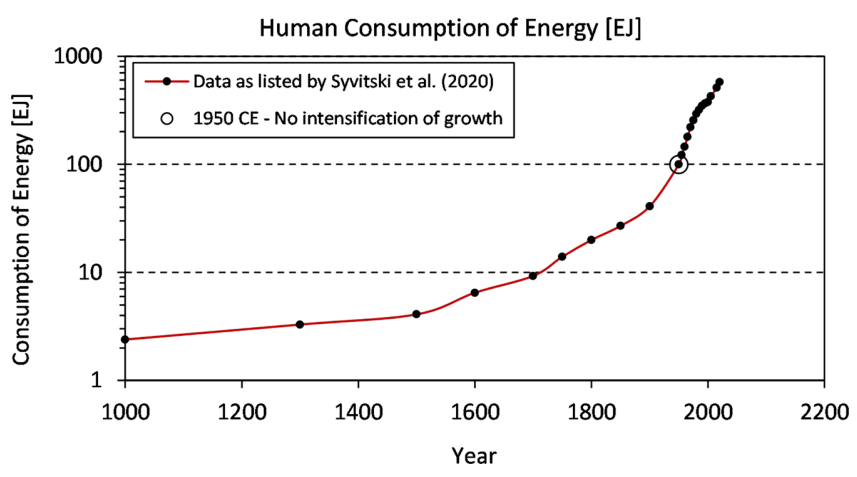

Figure 2. Human consumption of energy described by precisely the same data as listed by Syvitski et al. (2020), presented using semilogarithmic scales of reference. There was no intensification of growth around $1950 \mathrm{CE}$, no transition to an extraordinary consumption and no evidence to support the concept of the resultant geological impacts beginning around that time that could have initiated transition to the proposed new geological epoch. 
of data. Details of growth that cannot be seen in Fig. 1 are now more clearly revealed in Fig. 2. This figure confirms what was already suggested by the display presented in Fig. 1, that there was no sudden increase in the growth trajectory around $1950 \mathrm{CE}$. Nothing unusual happened around that year to support the expectation of compelling geological manifestation, nothing that could be used to determine the beginning of the proposed new geological epoch, nothing to expect strong geological impacts beginning around that time or around any other time within this range of data. Apart from some minor variations, normally encountered in data such as these, there was no clear and sustained change to a faster growth, no extraordinary acceleration in the production and consumption of energy. There is no indication of a transition from what could be called ordinary to an extraordinary consumption of energy. Growth around $1950 \mathrm{CE}$ was just the natural continuation of the earlier growth. It continued undisturbed until well after 1950 CE when it decelerated (see Supplementary material). Human consumption of energy cannot be, therefore, used in support of the concept of a transition to a new geological epoch.

\section{Growth of Human Population}

Historical data for the growth of human population were compiled by Manning (2008) and by the US Census Bureau (2018). Primary sources include: Taeuber and Taeuber (1949), United Nations (1953), Cook (1960), Durand (1967), Clark (1968), Durand (1974), Thomlinson (1975), Durand (1977), McEvedy and Jones (1978), Biraben (1980), Gallant (1990), Trager (1994), Haub (1995), Livi-Bacchi (1997) and Maddison (2010). Excellent data from $1950 \mathrm{CE}$ are available from the US Census Bureau (2021). Data between $1000 \mathrm{CE}$ and $2020 \mathrm{CE}$ are shown in Fig. 3. Growth of human population was increasing monotonically without any sign of a sustained intensification at any time. In particular, there was no sustained intensification of growth around $1950 \mathrm{CE}$. On the contrary, soon after that year, growth of human population started to slow down, as indicated by a gradually decreasing gradient (slope) of the growth trajectory (by the trajectory bending gradually downwards or to the right). It is well-known that growth of human population is now slowing down

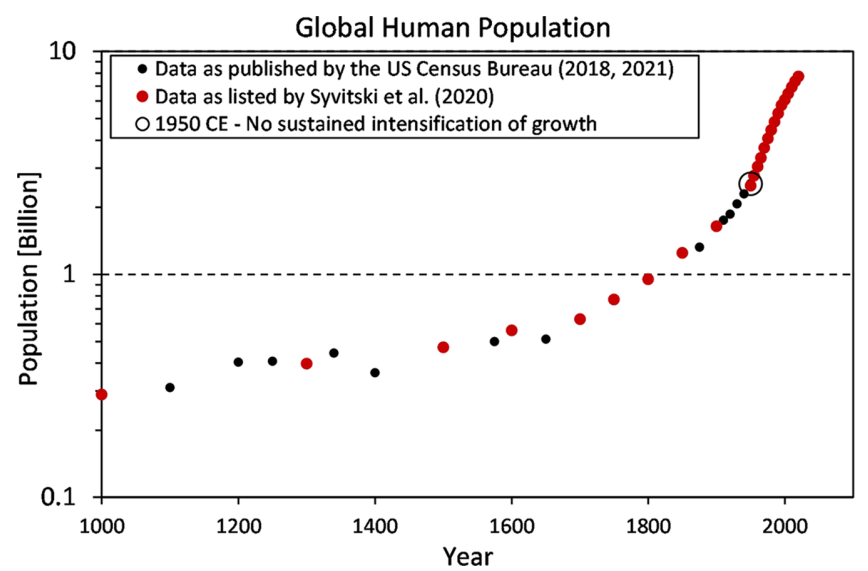

Figure 3. Data describing growth of human population. There was no sustained intensification of growth around 1950 CE. Soon after that year, growth trajectory decelerated and changed from the increasingly accelerating (bending upwards) to decelerating (bending downwards or to the right). These data cannot be used in support of a new geological epoch and of its assumed beginning around $1950 \mathrm{CE}$.
GDP and GDP/cap

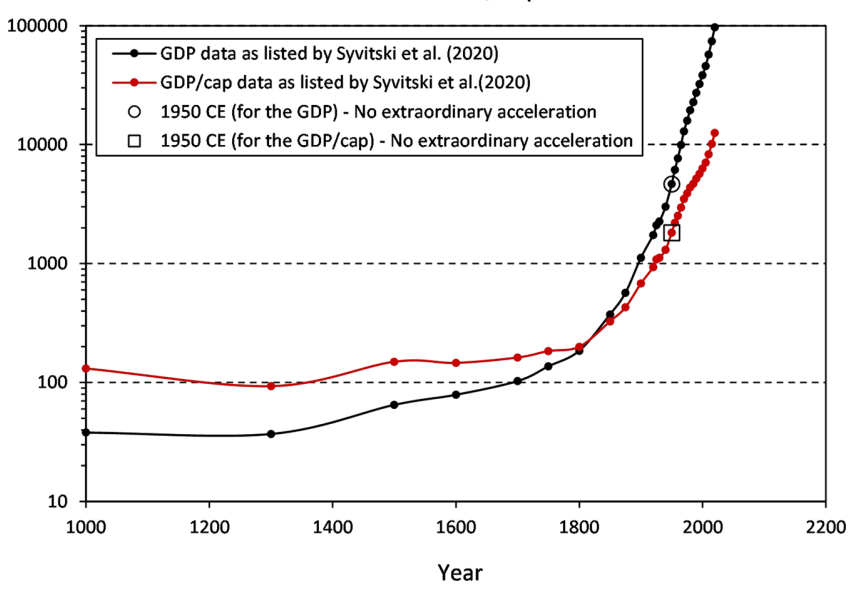

Figure 4. Data describing economic growth, as listed by Syvitski et al. (2020). Data for the Gross Domestic Product (GDP) are in billions of international 1990 dollars, and for the Gross Domestic Product per person (GDP/cap) in international 1990 dollars. Data show that there was no extraordinary acceleration in productivity and consumption around $1950 \mathrm{CE}$.

(see for instance US Census Bureau, 2021). With the slowing down growth of human population it is only natural to expect that human activities and impacts might be also slowing down, and indeed they are (Nielsen, 2021). This well-known deceleration of the growth of human population and the absence of sustained intensification around $1950 \mathrm{CE}$ or around any other recent time question the concept of the Anthropocene as a new geological epoch.

\section{Economic Growth}

Data describing economic growth, based on the estimates of De Long (1998) and listed by Syvitski et al. (2020), are displayed in Fig. 4. Gross Domestic Product (GDP) describes the overall production and consumption. Data for the GDP and GDP/cap (GDP per person) show that there was no extraordinary acceleration in consumption and productivity, which could have demonstrated how the Earth System departed from the Holocene Epoch since around $1950 \mathrm{CE}$. If the assumed extraordinary acceleration was supposed to demonstrate how the Earth System departed from its Holocene status, then the absence of this acceleration might suggest that there was no departure, no transition to a new geological epoch, described as the Anthropocene. Consequently, these data, the data for the other two key anthropogenic indicators (human consumption of energy and growth of human population), and the so-called Great Acceleration Data (Broadgate et al., 2014; see also Supplementary material), which demonstrated systematic decelerations (Nielsen, 2021), question the concept of the Anthropocene as a new geological epoch. They suggest that there was no human-induced geological transition.

\section{Other Indicators}

Other indicators listed by Syvitski et al. (2020) are: global reservoir capacity, global number of dams, atmospheric concentration of 


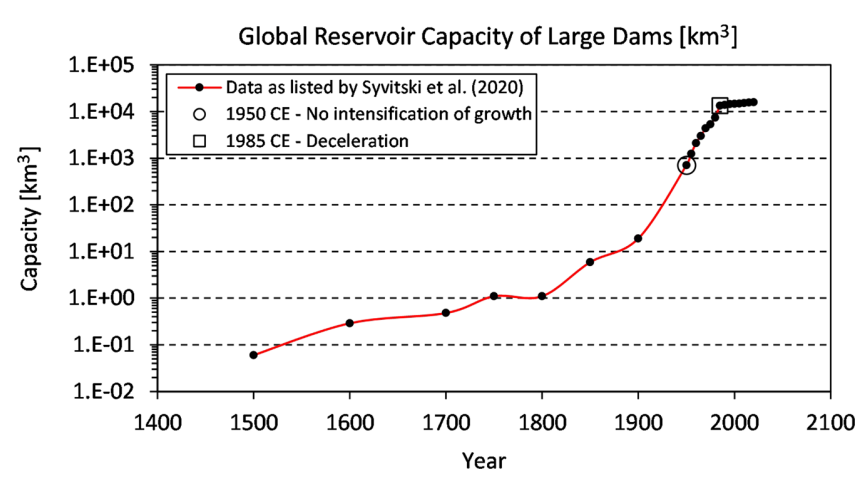

Figure 5. Growth trajectory for the global reservoir capacity, in cubic kilometres $\left(\mathrm{km}^{3}\right)$. There was no intensification (abrupt acceleration) of growth around $1950 \mathrm{CE}$, but there was deceleration (transition to a slower growth) towards the end of this trend.

carbon dioxide $\left(\mathrm{CO}_{2}\right)$, production of plastics, production of ammonia $\left(\mathrm{NH}_{3}\right)$, production of cement, and production of copper. Growth trajectory for the global reservoir capacity, in $\mathrm{km}^{3}$ (cubic kilometres), is shown in Fig. 5. There was no intensification of growth around 1950 CE. However, there was a deceleration from around $1985 \mathrm{CE}$ or maybe even earlier if it is logistic growth (David and Edwards, 2001), which is sometimes described as an S-shaped growth. It is a useful but imprecise description because it is possible to construct many other $\mathrm{S}$-shaped types of growth, which are not logistic. The prominent feature of the logistic growth is that it approaches asymptotically a certain maximum value (it levels off). Mathematical description of this type of growth is presented in the Supplementary material of the earlier publication (Nielsen, 2021). Its unique and characteristic feature, which distinguishes it from all other S-shaped types of growth, is that its growth rate decreases linearly with the size of the growing entity (in this case, with the reservoir capacity). In order to use this feature to identify logistic growth and to determine its parameters, it is essential to have better quality data at small time intervals, preferably every year.

Time-dependent increase of the global number of large dams is shown in Fig. 6. Data show a clear discontinuity. Data below $1700 \mathrm{CE}$ follow a distinctly different pattern of growth than data above this year. However, this feature is of no consequence for checking whether there was an intensification of growth around 1950 CE. Data show that there was no intensification of growth around that year, but a deceleration towards the end of the growth trajectory. Mathematical analysis of

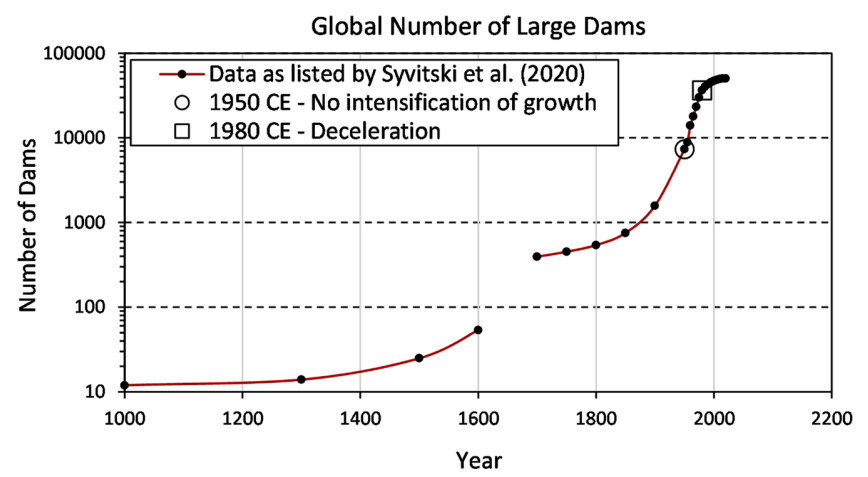

Figure 6. Growth trajectory for the number of large dams. There was no intensification (abrupt acceleration) of growth around 1950 $C E$, but there was a deceleration towards the end of this trend.

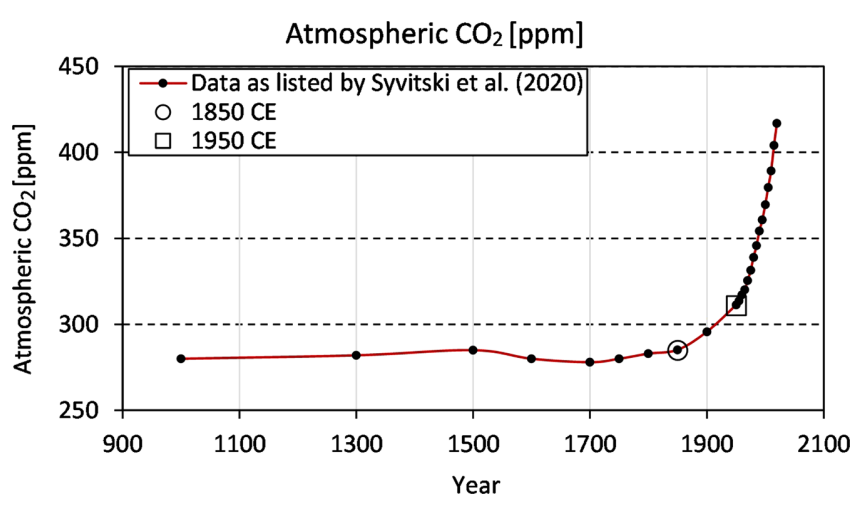

Figure 7. Data for the atmospheric concentration of carbon dioxide $\left(\mathrm{CO}_{2}\right)$, in parts per million (ppm), as listed by Syvitski et al. (2020). There was a strong and sustained intensification of growth commencing between around $1700 \mathrm{CE}$ and $1850 \mathrm{CE}$.

significantly better-quality of the so-called Great Acceleration Data (Broadgate et al., 2014) demonstrated that the increase in this region was following a logistic pattern of growth (Nielsen, 2021).

Data for the atmospheric concentration of carbon dioxide $\left(\mathrm{CO}_{2}\right)$, as listed by Syvitski et al. (2020), are shown in Fig. 7. Within this range of time, atmospheric concentration of $\mathrm{CO}_{2}$ was initially approximately constant. The average value between $1000 \mathrm{CE}$ and $1800 \mathrm{CE}$ was 280 ppm (parts per million). From around $1850 \mathrm{CE}$ or maybe even earlier, from around $1700 \mathrm{CE}$, atmospheric concentration of carbon dioxide started to increase. Excellent quality data listed by Broadgate et al. (2014), which commence from $1750 \mathrm{CE}$, show that there was no sharp increase during this early range of time.

Global annual production of plastics in million tonnes, Mt, is shown in Fig. 8. This growth trajectory cannot be used to check whether there was an intensification of growth in $1950 \mathrm{CE}$ because production of plastics commenced around that year. However, it is still interesting to inspect its growth trajectory because plastics have strong impact on the environment. Analysis of data shows that growth was initially along a fast-increasing exponential trajectory. (In a semilogarithmic display, exponential growth is represented by a straight line.) Growth decelerated around 1972 CE. After the deceleration it was also approximately exponential but slower. Initially, global annual production of plastics was increasing at $14 \%$ per year. Doubling time was approximately 5 years. After the deceleration, growth was increasing at approxi-

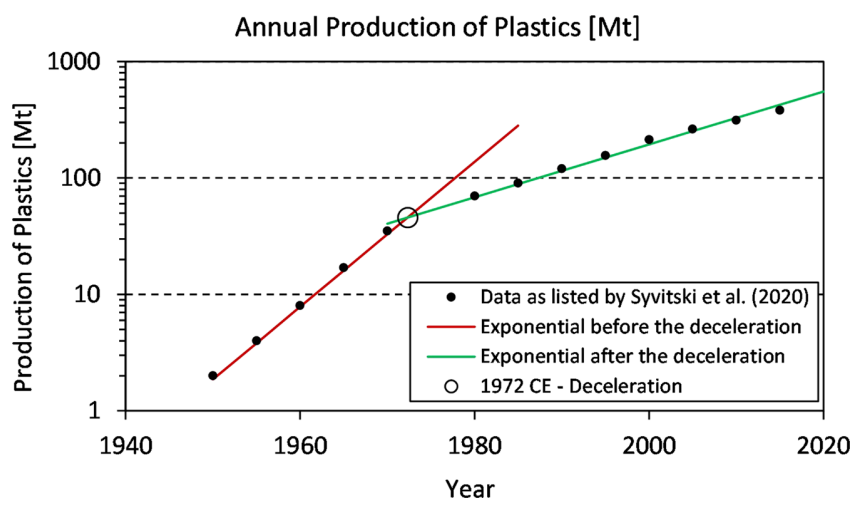

Figure 8. Global annual production of plastics in million tonnes (Mt). Data show a significant deceleration around 1972 CE. 


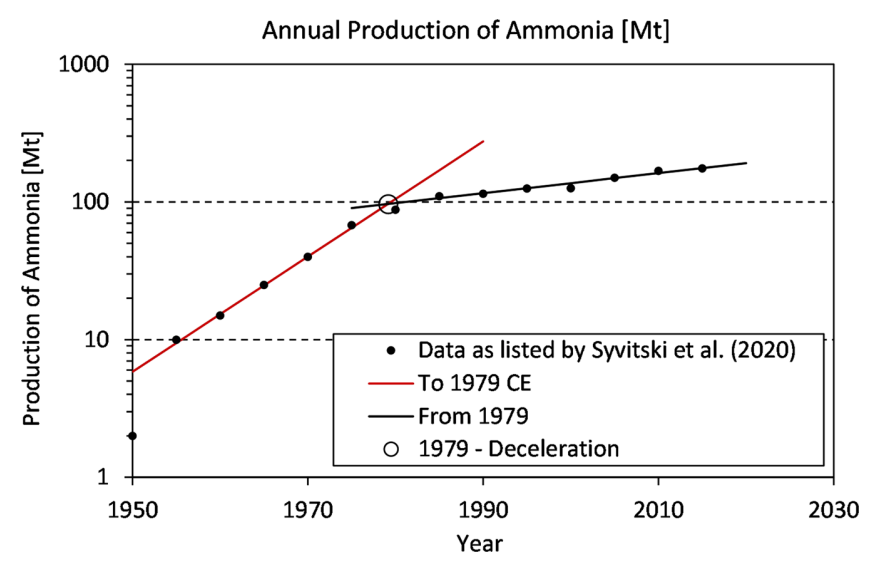

Figure 9. Global annual production of ammonia $\left(\mathrm{NH}_{3}\right)$ in million tonnes (Mt). Data show a significant deceleration in the growth trajectory around $1979 \mathrm{CE}$.

mately $5 \%$ per year, with the doubling time of about 14 years.

Global annual production of ammonia $\left(\mathrm{NH}_{3}\right)$ in million tonnes, $\mathrm{Mt}$, is shown in Fig. 9. Here again, as for the global production of plastics, data are available only from $1950 \mathrm{CE}$. The initial growth trajectory was increasing exponentially, at the annual rate of $9.6 \%$ with the corresponding doubling time of about 7 years. Around $1979 \mathrm{CE}$, growth decelerated and started to follow a significantly slower exponential trajectory, with the growth rate of about $1.7 \%$ and with the corresponding doubling time of about 41 years.

Growth trajectory describing the annual production of cement is shown in Fig. 10. There was no intensification of growth around 1950 CE. Data demonstrate a deceleration around 1965 CE. Initially, growth was increasing exponentially, with the growth rate of $6.8 \%$, corresponding to the doubling time of 10 years. From around $1965 \mathrm{CE}$, growth was again exponential but with a reduced growth rate of $4.4 \%$, corresponding to the doubling time of 15.7 years. Global annual production of copper in million tonnes, Mt, is shown in Fig. 11. Production appears to have been decelerated around $1850 \mathrm{CE}$, accelerated around $1900 \mathrm{CE}$, and decelerated again around $1970 \mathrm{CE}$. There was no intensification of growth around $1950 \mathrm{CE}$.

Syvitski at al. (2020) also presented a series of correlations in their Figs. 2 and 3. All of them were now closely inspected. They did not show even a single example of intensification of growth around 1950

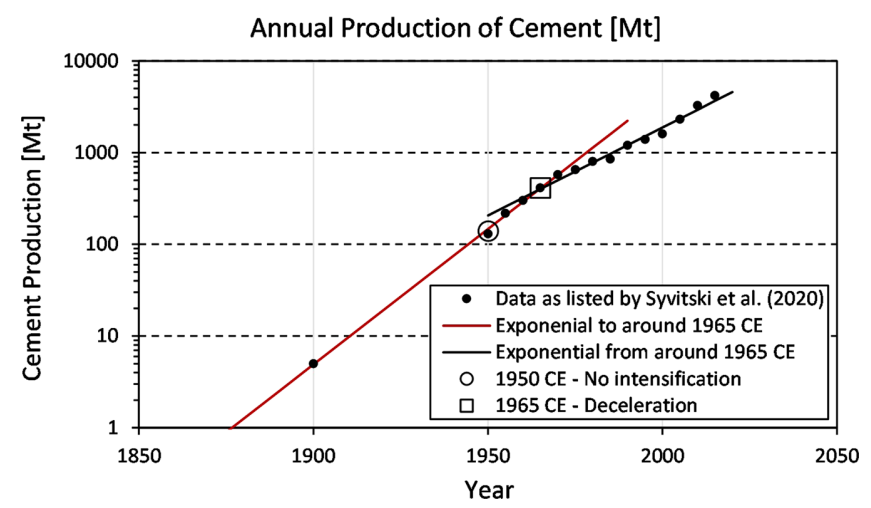

Figure 10. Global annual production of cement in million tonnes (Mt). There was no intensification of growth at any time, but deceleration around $1965 \mathrm{CE}$.

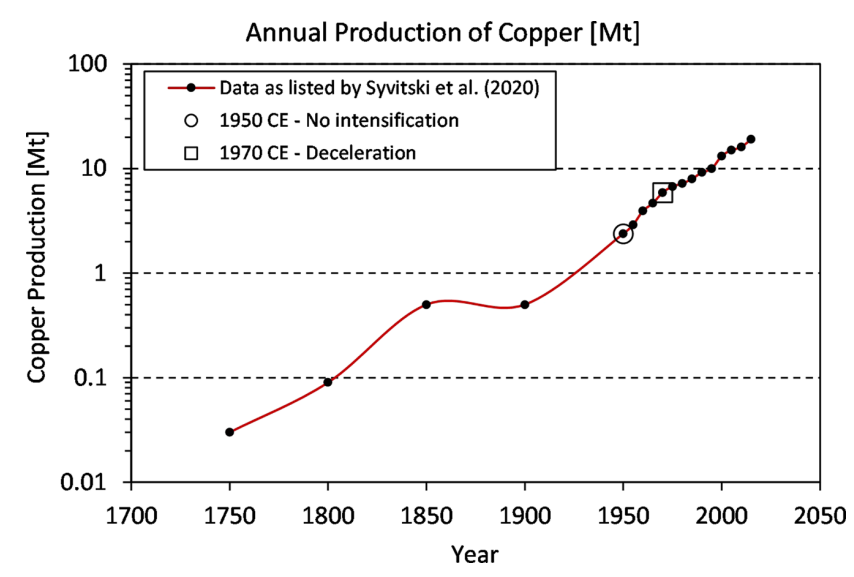

Figure 11. Global annual production of copper in million tonnes (Mt). There was no intensification of growth around 1950 CE but there was a deceleration around 1970 CE.

CE. However, for two of them, Syvitski et al. (2020) identified abrupt acceleration in the 1800s CE. These correlations are for the GDP/cap (Gross Domestic Product per person) and for the P/E ratio, both correlated with the growth of human population. The $\mathrm{P} / \mathrm{E}$ ratio is defined by Syvitski at al. (2020) as the GDP/cap divided by the per capita consumption of energy, which is, of course, just the GDP divided by the consumption of energy. Calculations of the per capita GDP and the per capita consumption of energy are unnecessary. These two correlations are shown in Figs. 12 and 13. The GDP/cap describes economic output or production and consumption per person, while the $\mathrm{P} / \mathrm{E}$ ratio describes economic output or production and consumption per unit of energy. Data presented in Figs. 12 and 13 show how these quantities depend on the size of human population. Syvitski et al. (2020) used the acceleration in the economic output in the 1800s CE as a justification for the earlier suggestion of the beginning of the Anthropocene around that time (Crutzen and Stoermer, 2000). However, the same correlations show that there was no intensification of growth around $1950 \mathrm{CE}$. The $\mathrm{P} / \mathrm{E}$ trajectory shows even a deceleration around that year. Consequently, using the same line of reasoning, these correlations indicate that there is no justification for claiming the beginning of the Anthropocene around $1950 \mathrm{CE}$.

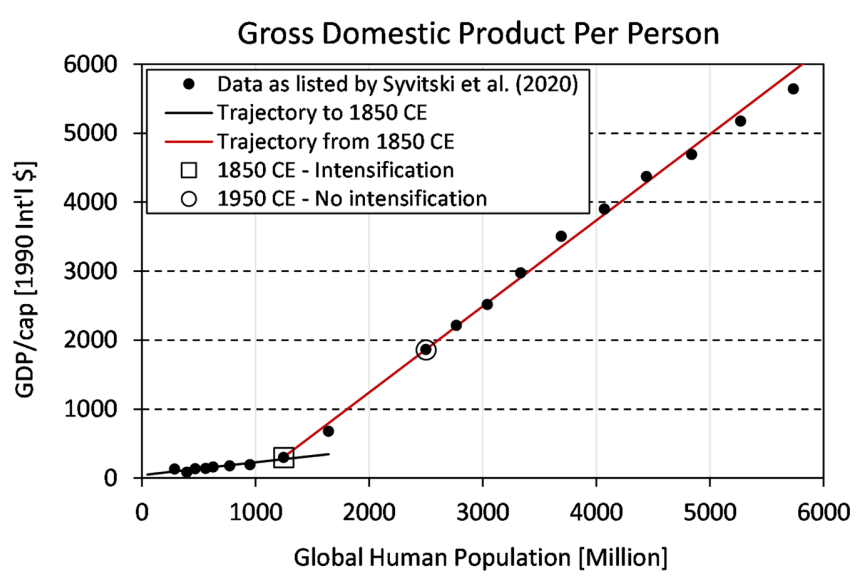

Figure 12. Global annual Gross Domestic Product per person (GDP/ cap) correlated with the size of human population. There was no intensification of growth around $1950 \mathrm{CE}$. 
P/E Ratio

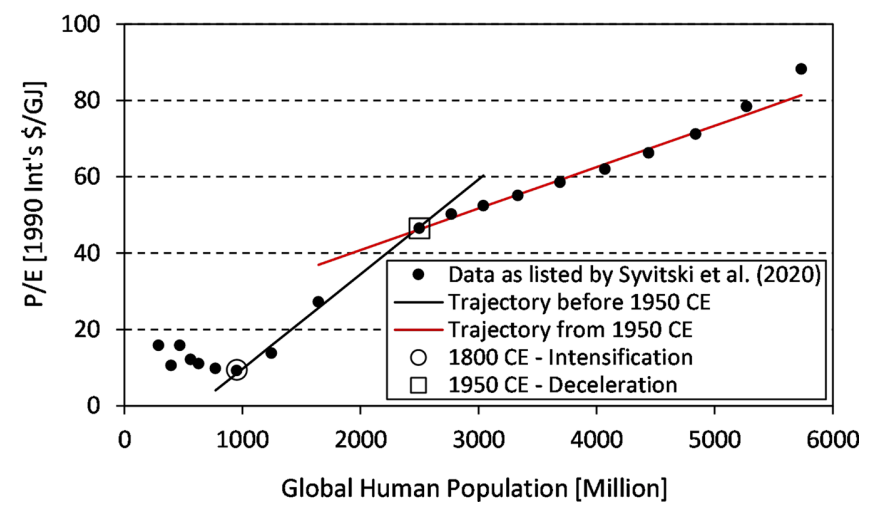

Figure 13. The P/E ratio (economic output per unit of energy) in 1990 International dollars per gigajoules (GJ) correlated with the size of human population. There was no intensification of growth around $1950 \mathrm{CE}$.

\section{Annual Growth Rate}

The only example of a sudden increase in $1950 \mathrm{CE}$, presented by Syvitski et al. (2020), is for the annual growth rate of human population when plotted as a function of the size of human population. Their calculations are reproduced in Fig. 14. They show a dramatic increase of the growth rate between $1950 \mathrm{CE}$ and $1955 \mathrm{CE}$. However, this large increase is not confirmed by the data of the US Census Bureau (2018, 2021) and by a study of Kremer (1993). The increase presented by Syvitski et al. (2020) is about twice as large as in these two cases. Another puzzling feature is the low value of $0.87 \%$ for the year 1950 CE presented by Syvitski et al. (2020) in their diagram and in their

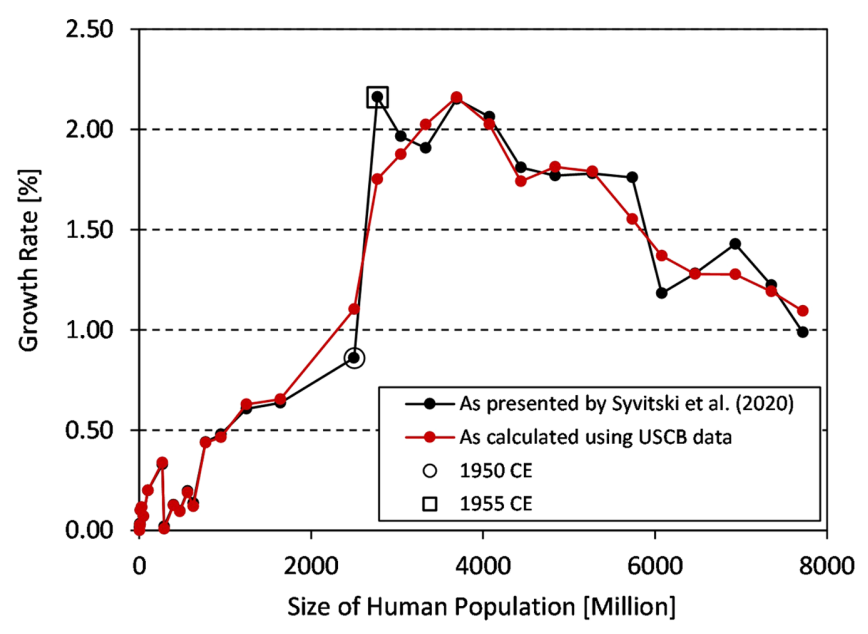

Figure 14. Annual growth rate for the global growth of human population plotted as a function of the size of population. The black line is the growth rate as published by Syvitski et al. (2020), while the red line is the growth rate calculated using data of the US Census Bureau (2018, 2021), indicated here as the USCB data. The increase in 1950 CE was not a transition to a sustained intensification of growth but to a sustained deceleration, as indicated by the gradually decreasing growth rate after this brief and faster increase. This increase was also a part of the earlier increasing trend. supplementary table. The origin of this value is unknown, but it is not confirmed even by the population data they used in their calculations. This unconfirmed low value makes the increase between $1950 \mathrm{CE}$ and $1955 \mathrm{CE}$ more dramatic. However, it does not matter whether this increase was large or small. Even their calculations show that this increase does not describe a sustained intensification of growth but a transition to sustained deceleration because growth rate was on average decreasing after $1955 \mathrm{CE}$ and thus describing the slowing-down pattern of growth. Furthermore, the increase between $1950 \mathrm{CE}$ and $1955 \mathrm{CE}$ was just a part of the continuing earlier increase of the growth rate.

\section{Geological Transitions}

It is essential to make a clear distinction between the Anthropocene as a new and unique time of strong human impacts on the environment and the Anthropocene as a new geological epoch. Strong anthropogenic impacts on the environment are not questioned, but only their expected unequivocal geological manifestations. Claiming that there was an extraordinary consumption of energy with the resultant geological impacts beginning around $1950 \mathrm{CE}$ or that there was an extraordinary acceleration in consumption and productivity, which demonstrated how the Earth System departed from the Holocene Epoch since 1950 $\mathrm{CE}$, or ever, does not appear to be the way geologists would react to these issues.

According to the International Stratigraphic Guide (Murphy and Salvador, 1999) and Gibbard (private communication, 2021), the fundamental requirement for the definition of a new division of geological time is that any evidence that is used to define a boundary and to characterise a unit must be preserved in the geological record, i.e., in deposits. Nothing else will do. This point concerns the whole geological record and not simply that of the Anthropocene proposal. In other words, it makes no difference whatsoever how much was produced or consumed, including the consumption of energy, from $1950 \mathrm{CE}$ onwards, or from any other recent time. If there is no evidence of these factors preserved in geological sequences, then no new unit can be defined, and no geological transition can be claimed. So, the amount of other data of any kind, no matter what, cannot be used in support of a claim of a geological transition. If data are not directly determinable from the rock/sediment record, they are of no consequence to geoscientists. However, in the case of the Anthropocene, as representing the assumed geological epoch, which by definition is supposed to have been caused by humans (Crutzen and Stoermer, 2000; Crutzen, 2002), trajectories describing human activities and impacts represent anthropogenic forces. Close inspection of these trajectories can give information about the intensity of these forces and whether they might be strong enough to be reflected in a clear stratigraphic evidence of geological transition.

\section{Summary and Conclusions}

The study published by Syvitski et al. (2020) has now been extended by carrying out close examination of data they have listed in their publication. The aim was to inspect time-dependent anthropogenic trajectories 
and search for the expected intensifications of growth around $1950 \mathrm{CE}$, which could be used to mark the beginning of the Anthropocene. Results of this investigation agree with the implicit information presented by Syvitski et al. (2020) that there is no convincing evidence of systematic intensifications of growth around that time. Analysis of these data also confirms the explicit evidence of the earlier study (Nielsen, 2021) that many growth trajectories describing human activities and impacts are now slowing down. This earlier study is now supported by new examples of systematic decelerations of growth.

The three most important indicators in this set of data are human consumption of energy, growth of human population and economic growth. Data describing human consumption of energy (Fig. 2) follow a gradually increasing trajectory without any indication of intensification and of a transition to a new pattern of growth that could be described as an extraordinary consumption resulting in geological impacts beginning around $1950 \mathrm{CE}$ or around any other recent year. Human consumption of energy started to decelerate shortly after this year. Data do not support the concept of the human-mediated geological transition. Data for the growth of human population (Fig. 3) also show that there was no sustained intensification of growth around $1950 \mathrm{CE}$. They confirm the well-known process of gradual deceleration of the growth of human population, which commenced shortly after 1950 CE. Data describing Gross Domestic Product (GDP) and the GDP per person (Fig. 4) show that there was no extraordinary acceleration in the human-generated production and consumption around $1950 \mathrm{CE}$ or around any other recent time. They also do not support the concept of a transition to a new geological epoch. Humangenerated production and consumption cannot be used to demonstrate that the Earth System departed from its Holocene status since around 1950 CE. Inspection of time-dependence of other data listed by Syvitski et al. (2020) leads to the same conclusion, as based on the examination of these three key indicators, that there was no systematic intensification of growth around $1950 \mathrm{CE}$. However, one example of time dependent trajectory shows a clear and sustained intensification of growth beginning between $1700 \mathrm{CE}$ and $1850 \mathrm{CE}$. It is for the atmospheric concentration of carbon dioxide. There is also an indication of intensification of growth in the 1800s CE for the economic output per person and for economic output per unit of energy expressed as a function of the size of human population. However, these two correlations show that there was no intensification of growth around $1950 \mathrm{CE}$. Data for the economic output per unit of energy show even deceleration around that year.

Results presented here and in the earlier publication (Nielsen, 2021) do not question the well-known and widely accepted evidence of the current strong human impacts on the environment, but they question whether these strong impacts are strong enough to have unequivocal geological manifestations, for two reasons. The first reason is the conspicuous absence of the expected systematic intensifications of human activities and impacts around $1950 \mathrm{CE}$ or around any other recent time that might have been representing a strong anthropogenic force. In general, human activities and impacts did not intensify around 1950 $\mathrm{CE}$ or around any other recent time. The second reason is the systematic presence of the opposite effect. Rather than showing systematic intensifications of growth, data show the presence of systematic decelerations, generally close to the time of the anticipated intensifications. For whatever reasons, the intensity of human activities and impacts started to decrease in the 1950s CE. These systematic decelerations undermine the proposal for a geological transition. Humans might not be as important for the existence of our planet as they appear to be. Anthropogenic forces, while having environmental impacts and strong environmental manifestations might not be strong enough to be reflected as unequivocal geological manifestations. Anthropocene might be just a new and unique time in human history, a transition to a new chapter in human existence, but not a new geological epoch.

\section{Data availability}

De Long (1998); Manning (2008) and references therein; Maddison (2010); Broadgate et al. (2014); Ritche and Roser, (2016); Nielsen (2017); US Census Bureau (2018) and references therein; Syvitski et al. (2020) and references therein; US Census Bureau (2021).

\section{Acknowledgement}

I want to thank Stan Finney, Phil Gibbard and Mike Walker for their comments and support. I am grateful to Reviewers of my manuscript for their helpful suggestions. I have full respect for Paul Crutzen, and I regret that anthropogenic data do not give a clear support for his concept of a new geological epoch. I declare no conflict of interest. This research was carried out without financial support.

\section{References}

Biraben, J.N., 1980, An essay concerning mankind's evolution. Journal of Human Evolution, v. 9, pp. 655-663, doi:10.1016/0047-2484(80)90099-8

Broadgate, W., Owen Gaffney, O., Deutsch, L., Ludwig, C., and Steffen, W., 2014, Great Acceleration. http://www.igbp.net/globalchange/greatacceleration.4.1b8ae20512db692f2a680001630.html [accessed 27 May 2021].

Clark, C., 1968, Population Growth and Land Use. St Martin's Press, New York, NY, $200 \mathrm{p}$.

Cook, R.C., 1960, World population growth. Law and Contemporary Problems, v. 25, pp. 379-388.

Crutzen, P.J., 2002, Geology of mankind. Nature, v. 415, p. 23. doi:10.1038/ $415023 \mathrm{a}$

Crutzen, P.J., and Stoermer, E.F., 2000, The "Anthropocene". Global Change Newsletter, v. 41, pp. 17-18.

David, H.A., and Edwards, A.W.F., 2001, Annotated Readings in the History of Statistics. Springer, New York, Berlin, Heidelberg, 252 p.

De Long, J.B., 1998, Estimates of World GDP, One Million B.C. - Present. https://delong.typepad.com/print/20061012_LRWGDP.pdf, [accessed 28 May 2021].

Durand, J.D., 1967, A long-range view of world population growth. The Annals of the American Academy of Political and Social Science: World Population, v. 369, pp. 1-8. doi:10.1177/000271626736900101

Durand, J.D., 1974, Historical Estimates of World Population: An Evaluation. Analytical and Technical Reports, Number 10, University of Pennsylvania, Population Center, Philadelphia, PA, $72 \mathrm{p}$.

Durand, J.D., 1977, Historical estimates of world population: An evaluation. Population and Development Review, v. 3, pp. 256-293.

Gallant, R.A., 1990, The Peopling of Planet Earth: Human Growth through the Ages. Macmillan Publishing Company, New York, NY, 163 p.

Hamilton, C., 2015, Getting the Anthropocene so wrong. The Anthropocene Review, v. 2, pp. 102-107. 
Haub, C., 1995, How many people have ever lived on earth?. Population Today, v. 23, pp. 4-5.

Kremer, M., 1993, Population growth and technological change: one million B.C. to 1990. Quarterly Journal of Economics, v. 108, pp. 681-716. doi:10.2307/2118405

Livi-Bacci, M., 2007, A Concise History of World Population (2nd edition). Blackwell Publishers, Malden, MA, $296 \mathrm{p}$.

Maddison, A., 2010, Historical Statistics of the World Economy: 1-2008 AD. http://www.ggdc.net/maddison/Historical_Statistics/horizontalfile_02-2010.xls, [accessed 28 May 2021].

Manning, S., 2008, Year-by-Year World Population Estimates: 10,000 B.C. to 2007 A.D. http://www.scottmanning.com/content/year-by-yearworld-population-estimates/ [accessed 28 May 2021].

McEvedy, C., and Jones, R., 1978, Atlas of World Population History. Penguin Books Ltd., Harmondsworth, Middlesex, England, 368 p.

Murphy, M.A., and Salvador, A., eds., 1999, International stratigraphic guide an abridged version. Episodes, v. 22, pp. 255-271.

Nielsen, R.W., 2017, Economic growth and the growth of human population in the past 2,000,000 years. Journal of Economic Bibliography, v. 4, pp. $128-149$.

Nielsen, R.W., 2021, The Great Deceleration and proposed alternative interpretation of the Anthropocene. Episodes, v. 44, pp. 107-114. doi:10.18814/epiiugs/2020/020076

Ritchie, H., and Roser, M., 2016, Energy production and changing energy sources. https://ourworldindata.org/energy-production-and-changingenergy-sources/[accessed 28 May 2021].
Syvitski, J., Waters, C.N., Day, J., Milliman, J.D., Summerhayes, C., Steffen, W., Zalasiewicz, J., Cearreta, A., Gałuszka, A., Hajdas, I., Head, M.J., Leinfelder, R., McNeill, J.R., Poirier, C., Rose, N.L., Shotyk, W., Wagreich, M., and Williams, M., 2020, Extraordinary human energy consumption and resultant geological impacts beginning around $1950 \mathrm{CE}$ initiated the proposed Anthropocene Epoch. Communications Earth and Environment, v. 1, pp. 13, doi:10.1038/s43247-020-00029-y

Taeuber, C., and Taeuber, I.B., 1949, World population trends. Journal of Farm Economics, v. 31, pp. 237-250.

Thomlinson, R., 1975, Demographic Problems, Controversy Over Population Control (2nd edition). Dickenson Pub., Encino, CA, 244 p.

Trager, J., 1994, The People's Chronology: A Year-by-Year Record of Human Events from Prehistory to the Present. Henry Holt and Company, New York, NY, $1251 \mathrm{p}$.

United Nations, 1953, The Determinants and Consequences of Population Trends. Population Studies, no. 17. United Nations, New York, 406 p. https://www.un.org/development/desa/pd/sites/www.un.org.development.desa.pd/files/files/documents/2020/Jan/un_1953_determinantsandconsequencesofpopulationtrends_0.pdf [accessed 28 May 2021].

US Census Bureau, 2018, Historical Estimates of World Population. https:// www.census.gov/data/tables/time-series/demo/international-programs/ historical-est-worldpop.html [accessed 28 May 2021].

US Census Bureau, 2021, International Data Base (IDB) Data Tool. https: //www.census.gov/data-tools/demo/idb/\#/country?YR_ANIM=2021 [accessed 28 May 2021].

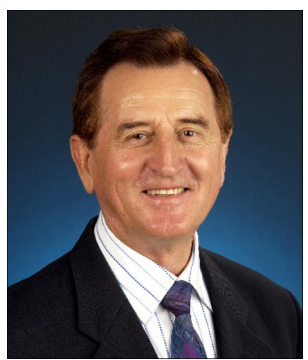

Ron W. Nielsen, aka Jan Nurzynski, is a retired nuclear scientist. After his retirement he became interested in environmental issues. He published a book containing a large body of data describing human activities and impacts. This book was endorsed by Paul Crutzen, who introduced him to the concept of the Anthropocene. Ron Nielsen extended his work by focusing on the investigation of the dynamics of growth of human population and of economic growth, both global and regional. He introduced a concept of the force of growth and used it to explain the mechanism of the historical growth of human population and of economic growth. He also formulated a mathematical procedure of data analysis and forecasting based on using the force of growth. 